\title{
The Degree of Utilizing E-Assessment Techniques at Prince Sattam Bin Abdulaziz University: Faculty Perspectives
}

\author{
Asma A. ALShaikh \\ Associate Professor of Science Instruction, \\ College of Education, \\ Prince Sattam bin Abdulaziz University, \\ Saudi Arabia
}

DOI: https://doi.org/10.36941/jesr-2020-0o81

\section{Abstract}

Accomplishing higher education development entails the use of the available technological means and innovative teaching and evaluation methods. Further, developing modern techniques for assessment is integral for achieving the intended learning outcomes and enhancing the alumnus' capabilities for meeting the digital era requirements. The current study thus aims to identify the degree of utilizing the techniques of e-assessment from the perspective of faculty members in the College of Education at Prince Sattam Bin Abdulaziz University, Saudi Arabia. It also seeks to identify statistically significant differences in the participants' responses due to gender, academic degree, and years of experience. The analytical descriptive approach was adopted and applied to a sample of 70 faculties at the College of Education, Prince Sattam Bin Abdulaziz University. A questionnaire was developed to include three domains: diagnostic e-assessment, formative e-assessment, and summative e-assessment. The findings demonstrated that there was a low degree of utilizing diagnostic e-assessment and a medium degree of utilizing both formative and summative e-assessments from faculty perspectives. In addition, there were no statistically significant differences in the participants' responses due to gender, academic degree, and years of experience. The study recommends expanding the utilization of e-assessment techniques in Saudi universities and conducting scientific research to identify faculty members' training needs in the field of e-assessment.

Keywords: E-assessment, diagnostic e-assessment, formative e-assessment, summative e-assessment, higher education

\section{Introduction}

In the light of the rapid scientific and technological changes witnessed in the third millennium, higher education development becomes a necessity. Graduating of individuals capable of facing the future challenges requires utilizing the modern technologies available to improve the quality of the teaching, learning, and evaluation processes. In Saudi context, meeting the requirements of higher education development is one of the main objectives of Saudi vision 2030.

Evaluation practices adopted by higher education institutions are a basic standard for quality assurance. Due to the emergence of innovative teaching and learning strategies and the quick evolution of e-learning and distant education, in addition to the challenges facing higher education, such as the diversity of specializations and the increasing number of students, varied techniques of evaluation and assessment have been introduced (Walker, Topping \& Rodrigues, 2008). Furthermore, 
there are many disadvantages associated with the traditional methods of evaluation, including inappropriateness to measure various learning outcomes, examiner bias, wasting a lot of time and effort in the examination processes (i.e. preparation, marking, monitoring and grading) in addition to the high cost of examination papers, printing, and security. Additionally and as expressed by Baker and Gordon, the traditional system of assessment needs to be transformed into a more continuous process aimed at enhancing learners' acquisition, understanding, and application of knowledge (2014). The utilization of e-assessment techniques proves effective in overcoming the disadvantages of the traditional methods of evaluation and supporting the teaching and learning process (Appiah \& Tonder, 2018; Ayo, Akinyemi, Adebiyi \& Ekong, 2007; Schultz, 2009).

As defined by Appiah and Tonder, e-assessment is an end-to-end electronic process in which Information and Communication Technology (ICT) are employed in all the evaluative stages and activities (2008). ICT are utilized to accomplish all the tasks and procedures of the various stages of assessment, including examination preparation as well as the marking, grading and conducting of statistical analysis of the results (Osuji, 2017).

Stodberg (2012) argues that e-assessment means the employment of ICT to implement the whole process of assessment, i.e. from designing evaluative electronic tasks to storing students' results. It thus supports the evaluation process and helps achieve the intended learning and teaching objectives according to specific and precise scientific standards (Al-Anzi, 2019).

Zaytoon (2005) explains that the examination questions are set up by the aid of computer tools and sent to the student, who receives, answers, and resends the answers via the Internet. After marking, the feedback and the mark are sent to the student. In sum, e-assessment is a form of pedagogic evaluation emerged in response to ICT revolution and the immense development of teaching, learning, and evaluation processes. Evaluation is a comprehensive process intended to measure varied learning outcomes, including the cognitive, emotional and skillful aspects of the educational process. Accordingly, diverse ICT-based methods, tools, and applications are developed for enabling the assessment of learners inside and outside the classrooms.

While different tools and techniques are utilized in traditional assessment and e-assessment, both of them include three successive stages: Pre- or diagnostic e-assessment, formative e-assessment and final or summative e-assessment (Al-Asr, 2015; Al-Gharib, 2009; Al-Ruqy, 2017). Diagnostic eassessment aims to evaluate the learner's entry behavior by identifying his/her previously acquired knowledge, attitudes and skills, which are perquisites for learning a specific subject. It can be conducted by various methods and tools such as electronic concept maps, pretests, assignments and KWL strategy.

Formative e-assessment measures the learner's academic progress and achievement in the leaning activities and tasks. It is an ongoing evaluation conducted during the learning process and depends on providing feedbacks to the learner. There are various techniques of formative eassessment, including electronic assignment, blogging, projects, discussions, quizzes, portfolios, conferences and brochures. Balini (2015) recommends utilizing online formative assessment in higher education because it provides the learners with equal opportunities for building and sharing knowledge via discussion forums. Further, faculty can set up authentic evaluation activities relevant to students' real lives using transparent analytical models that help the learner understand the expected level of achievement. Providing immediate feedback and ongoing useful comments by faculties and peers is critical for the advance of the teaching and learning process.

Summative e-assessment is conducted to evaluate the level of the learner's total achievement of the learning tasks. Summative e-assessment can be conducted using various techniques, including eexamination, performance skills, and accurate records.

Furthermore, e-assessment affords many synchronous and asynchronous techniques and tools that can be used in all forms of evaluation and enables the measurement of different learning outcomes. These techniques include:

E-Tests: enable the faculty to assess the performance of the learners by utilizing the different forms of essay questions and substantive questions, such as multiple-choice and true or false 
questions. They are easy to mark and the results can be instantly publicized among learners (Abdelatti, 2015).

Web Quizzes: take a relatively short time (about 15 minutes) and measure the learner's achievement of specific part of the study content through answering quick questions such as true or false, multiple-choice, gap-filling, etc. The learner receives an instant e-feedback on his/her performance (Zaytoon, 2005).

Question pools: A database of questions stored in a limited storage media on a computer or on a website. According to Zaytoon (2005), there are two types of question pools:

a. Open Item Bank: Questions available for both teachers and learners who can utilize its questions in various forms of assessment.

b. Secure Item Bank: learners cannot access these questions because they are available only for authorized officials to prevent the leakage of questions.

The faculty can develop a question pool and thus using different sets of questions with each learner to reduce cheating or circulating answers among the learners. The faculty also can employ question pools in preparing electronic assignments or tests (Alsaadon, 2017). Honarmand (2009) highlighted the significance of utilizing e-tests in the assessment of university students, which requires developing a database of question pools.

E-assignments: tasks and activities assigned to learners required for passing the course, such as projects, reports, exercises, presentations, etc. The faculty assesses the performance of the learner and provides him/her with an online feedback (Zaytoon, 2005).

E-Portfolios (e-packages): a collection of digital evidence on the performance of the learner, including illustrations, achievements and sources saved on CDs or a website (Al-Nagem, 2016).

Questionnaires or surveys: tools employed to identify students' opinions on a certain topic or issue (Al-Asar, 2015).

Discussion forums: allow students to hold a discussion and to share information with each other or with a faculty. Balini (2015) recommends the activation of discussion forums on Blackboard LMS and in virtual classes since they proved effective in achieving positive results among learners through increasing their ability to raise questions, think out of the box, reflect on the learning content, and focus to achieve the aspired outcomes.

Interviews: can be conducted synchronously with the learner via texting, online chatting, or video conference (Abdulaziz, 2008).

\section{Literature Review}

Several previous studies highlighted the benefits of utilizing the techniques of e-assessment. Appiah and Tonder (2018) reviewed the literature that addressed e-assessment and summarized its merits, such as objectivity, conducting assessment on time, providing immediate feedback, and flexibility, i.e. learners can perform the assessing activities at the time and place appropriate for them. It also contributes to reducing the expenses of printing the examination papers and facilitating the amendments of errors without any additional costs. More significantly, technological tools can be adapted to help learners with disabilities, such as enlarging the font of the text or using headphones, among others.

For the faculty, e-assessment techniques facilitate the conduction of organized and integrated evaluation process as the items, timing and controls of the assessment can be arranged in accordance with the work circumstances. Further, the preparation of e-assessment tasks consumes less time than the traditional tasks, so the faculty can accomplish many other educational and research tasks that enhance the effectiveness of the learning process (Reju \& Adesina, 2009). As emphasized by Strodberg (2012), the faculty can save time and effort by utilizing e-assessment tools, such as establishing automatic e-assessments, providing immediate feedback to students and adapting tests to support the learning process, in addition to enhancing the assessment of knowledge and skills that are difficult to be evaluated by the traditional techniques. Thus, e-assessment contributes to 
conducting a total evaluation of the performance of students in different learning outcomes using tools and techniques appropriate to their academic level and abilities. As asserted by Abdelatti, faculty as well as university students prefer e-assessment more than traditional assessment because it saves time and effort (2015). As such, there are positive attitudes towards the use of the varied techniques of e-assessment among students and faculty in higher education (Aganzouri, 2017; AlJadea, 2017; Alsaadon, 2017).

Al-Anzi (2019) concluded that there was a medium degree of utilizing e-assessment techniques among teachers of social studies and civic education at middle school. The results also demonstrated no statistically significant differences in the degree of the participants' use of e-assessment techniques due to academic qualification, e-courses attended, and years of experience.

Thubaiti (2018) employed the analytical descriptive approach to study the relationship between the assessment methods utilized and the quality of the learning outcomes at Shaqra University. The results showed that there was a low degree of utilizing modern techniques of assessment among faculty. There were no statistically significant differences due to gender and years of experience, while there were statistically significant differences due to specialization and academic degree in favor of scientific specialization and professor, respectively. However, in Al-Jouf University, there were positive attitudes towards Blackboard e-assessment tools among faculties who expressed their need for more training on the employment of e-assessment tools (Aganzouri, 2017).

Al-Jadea revealed positive attitudes towards the utilization of e-tests among faculty at Tabuk University and identified a set of obstacles hindering its activation. The results showed also statistically significant differences in the sample responses due to gender and specialization in favor of females and theoretical specialization, respectively (2017). In the Saudi Electronic University, Alsaadon (2017) concluded that students were satisfied with the use of the e-assessment techniques in terms of enhancing self-learning, avoiding bias, and receiving immediate feedback.

Al-Hirdi (2017) concluded a medium degree of employing e-assessment tools at high schools in Riyadh and introduced a proposal for overcoming the technical, physical and administrative constraints hindering its use. Al-Ruqy; however, revealed a low degree of utilizing the techniques of diagnostic, formative and summative e-assessment among middle school teachers of Natural Science in Riyadh.

As demonstrated by Atallah (2016), students at Mansoura University adopted positive attitudes towards e-assessment with no statistically significant differences due to academic level and gender and statistically significant differences due to scientific specialization. For faculty members, they take negative attitudes towards e-assessment with no statistically significant differences due to years of experience and statistically significant differences due to specialization. Both students and faculty agreed to several obstacles hindering the application of e-assessment in higher education.

The development of higher education requires promoting the teaching, learning and evaluation processes. E-assessment techniques have become essential for overcoming the disadvantages of the methods of traditional assessment and elevating the level of alumnus. Accordingly, previous studies have dealt with e-assessment in various educational contexts covering many themes such as attitudes of faculty and student towards e-assessment and the obstacles hindering its implementation. However, the current study seeks to measure the degree of utilizing the techniques of e-assessment among faculty in the College of Education at Prince Sattam bin Abdulaziz University.

In Saudi context, national universities are making efforts to develop the system of higher education and improve the aspired learning outcomes. Evaluation is a fundamental component of any educational system and the only way for diagnosing weakness and figuring out a remedy (Fathallah, 2006). However, previous studies emphasized that traditional evaluation methods are still prevalent in most Saudi universities (Abu-Aish, 2016; Aganzouri, 2017; Thubaitt, 2018). As highlighted by Ahmad (2016) and Aboukhatwa (2013), faculty should be encouraged to use e-assessment due to its effectiveness in raising learning motivation among students. Al-Shammari, Abdulaziz and Muhammad recommended spreading the culture of e-assessment in higher education institutions by developing the organizing politics and affording training courses for faculty in the use of e- 
assessment techniques.

As Prince Sattam bin Abdulaziz University endeavors to develop its administrative and academic performance by supporting its electronic systems, this study identifies the degree of utilizing e-assessment from faculty perspectives through answering the following main question :

What is the degree of utilizing the techniques of e-assessment at the College of Education, Prince Sattam bin Abdulaziz University from faculty perspectives?

The following sub-questions are derived:

1. What is the degree of utilizing diagnostic e-assessment techniques at the College of Education, Prince Sattam bin Abdulaziz University from faculty perspectives?

2. What is the degree of utilizing formative e-assessment techniques at the College of Education, Prince Sattam bin Abdulaziz University from faculty perspectives?

3. What is the degree of utilizing summative e-assessment techniques at the College of Education, Prince Sattam bin Abdulaziz University from faculty perspectives?

4. Were there statistically significant differences at the significance level of $\alpha \leq 0.05$ in the participants' mean responses to the degree of utilizing e-assessment techniques due to gender, academic degree, and years of experience?

\section{Methodology and Procedures}

Method: To achieve the study objectives, the analytical descriptive approach was adopted.

Sampling: The study population comprised 166 faculties at the College of Education, Prince Sattam bin Abdulaziz University in Al-Kharj region, Saudi Arabia during the second semester of the academic year $2019 / 2020$. The sample consisted of 70 faculties, i.e. $42 \%$ of the population. Table 1 illustrates participants' distribution according to gender, academic degree, and years of experience.

Table 1: Sample distribution according to gender, academic degree, and years of experience

\begin{tabular}{|l|l|c|c|}
\hline Variable & Number & Percentage \\
\hline \multirow{3}{*}{ Gender } & Male & 31 & $44 \%$ \\
\cline { 2 - 4 } & Female & 39 & $56 \%$ \\
\hline \multirow{3}{*}{ academic degree } & Assistant Professor & 34 & $21 \%$ \\
\cline { 2 - 4 } & Associate professor & 27 & $50 \%$ \\
\cline { 2 - 4 } & professor & 9 & $29 \%$ \\
\hline \multirow{3}{*}{ years of experience } & $>5$ yrs & 16 & $23 \%$ \\
\cline { 2 - 4 } & $>10$ yrs & 32 & $46 \%$ \\
\cline { 2 - 4 } & $<10$ yrs & 22 & $31 \%$ \\
\hline
\end{tabular}

Instrument: The author prepared a questionnaire to measure the degree of utilizing e-assessment techniques at the College of Education, Prince Sattam bin Abdulaziz University from faculty perspectives. It comprised 24 items and 3 main domains: diagnostic e-assessment, formative eassessment and summative e-assessment. The initial instrument was prepared in the light of previous studies that dealt with e-assessment at different educational stages, including Al-Ruqy (2017), Ahamed (2016), Al-Jadea (2017), Al-Hirdi (2017), and Aganzouri (2017).

Face validity: To verify the instrument validity and appropriateness to the study objectives, it was submitted to six examiners specialized in curricula and instruction, educational technology and educational psychology. In the light of their comments, the questionnaire was modified by adding one more item to the first domain and another item to the second domain and deleting two items from the third domain .

Internal validity: the questionnaire was applied to a pilot sample of 20 faculties and the correlation coefficients between the score of each item and the total score of its domain were calculated as shown in Table 2. 
Table 2: Correlation coefficients between each item score and its domain total score

\begin{tabular}{|c|c|c|c|c|c|}
\hline \multicolumn{2}{|c|}{ First domain } & \multicolumn{2}{|c|}{ Second domain } & \multicolumn{2}{|c|}{ Third domain } \\
\hline Item & Correlation coefficient & Item & Correlation coefficient & Item & Correlation coefficient \\
\hline 1 & $0.890^{* \pi}$ & 7 & $0.512^{*}$ & 16 & $0.641^{* \pi}$ \\
\hline 2 & $0.873^{* \pi}$ & 8 & $0.847^{* \pi}$ & 17 & $0.558^{* \pi}$ \\
\hline 3 & $0.807^{* \pi}$ & 9 & $0.789^{* \pi}$ & 18 & $0.709^{* \pi}$ \\
\hline 4 & $0.797^{* \pi}$ & 10 & $0.743^{* \pi}$ & 19 & $0.682^{* \pi}$ \\
\hline 5 & $0.608^{* \pi}$ & 11 & $0.851^{* \pi}$ & 20 & $0.481^{* \pi}$ \\
\hline 6 & $0.816^{* \pi}$ & 12 & $0.641^{* \pi}$ & 21 & $0.626^{* \pi}$ \\
\hline & 13 & $0.808^{* \pi}$ & 22 & $0.729^{* \pi}$ \\
\cline { 2 - 6 } & & 14 & $0.825^{* \pi}$ & 23 & $0.537^{* *}$ \\
\cline { 2 - 6 } & & 15 & $0.692^{* \pi}$ & 24 & $0.656^{* *}$ \\
\hline
\end{tabular}

significant at the level of 0.01

significant at the level of 0.05

According to table 1, correlation coefficients between the score of each item and its total domain score were statistically significant at the levels of 0.01 and 0.05 . The correlation coefficients between each domain score and the total score of the questionnaire were calculated as demonstrated in table 3.

Table 3: Correlation coefficients between each domain score and the questionnaire total score

\begin{tabular}{|l|c|}
\hline Domain & Correlation coefficient \\
\hline Diagnostic e-assessment & $0.869^{*}$ \\
\hline Formative e-assessment & $0.90{ }^{* *}$ \\
\hline Summative e-assessment & $0.70{ }^{* *}$ \\
\hline
\end{tabular}

Table 3 illustrates that correlation coefficients between the score of each domain and the questionnaire total score were significant at the level of o.o1, indicating a highly internal consistency.

Reliability: Cronbach's Alpha coefficients were calculated as indicated in table 4.

Table 4: Reliability coefficients for the questionnaire

\begin{tabular}{|l|c|}
\hline Domain & Reliability Coefficient \\
\hline Diagnostic e-assessment & 0.896 \\
\hline Formative e-assessment & 0.895 \\
\hline Summative e-assessment & 0.804 \\
\hline Total & 0.920 \\
\hline
\end{tabular}

Cronbach's coefficients for the domains of the questionnaire ranged between $0.804-0.896$ and the total questionnaire reached 0.920 , indicating its reliability and suitability to the study objectives.

The final questionnaire consisted of two sections. The first section designed to collect the participants' data, including name, gender, academic degree, and years of experience .The second section contained 24 items and 3 domains: Diagnostic e-assessment (6 items), formative e-assessment (9 items), and summative e-assessment (9 items).

Statistical processing: Pearson correlation coefficient and Cronbach's alpha coefficient were applied to verify the questionnaire validity and reliability. Frequencies and percentages were obtained to calculate the participants' responses to the items of the questionnaire. Independent-samples T-test was calculated to identify the significance of differences in the participants' responses according to gender. ANOVA was calculated to identify the significance of differences in the participants' 
responses according to academic degree and years of experience.

A five-point scale was utilized to measure the participants' responses and the mean relative weight was calculated by dividing the range $(5-1=4)$, getting the category length by dividing the range (4) to the number of categories (5), i.e. the category length $=0.8$ added to the smallest degree in the scale (1). Table 5 illustrates the scales of the participants' responses and the mean relative weight for each response.

Table 5: Rating scale of the participants' responses to the questionnaire

\begin{tabular}{|l|c|c|c|c|c|}
\hline Degree & Very high & high & Medium & low & Very low \\
\hline score & 5 & 4 & 3 & 2 & 1 \\
\hline relative weight & $4.2-5$ & $3.4-<4.2$ & $2.6-<3.4$ & $1.8-<\mathbf{2 . 6}$ & $\mathbf{1}-<\mathbf{1 . 8}$ \\
\hline
\end{tabular}

\section{Results and discussion}

To answer the first question, What is the degree of utilizing diagnostic e-assessment techniques at the College of Education, Prince Sattam bin Abdulaziz University from faculty perspectives? The participants' responses to the first domain of the questionnaire were analyzed as shown in table 6.

Table 6: The participants' responses to the first domain of the questionnaire

\begin{tabular}{|c|c|c|c|c|c|}
\hline S. & Diagnostic e-assessment & \begin{tabular}{|c|}
$\begin{array}{c}\text { Arithmetic } \\
\text { mean }\end{array}$ \\
\end{tabular} & $\begin{array}{r}\text { standard } \\
\text { deviation }\end{array}$ & Degree & Rank \\
\hline 1 & I use diagnostic e-tests prior to teaching the course & 1.83 & 0.92 & Low & 6 \\
\hline 2 & $\begin{array}{l}\text { I use electronic concept maps to reveal the learners' previously acquired } \\
\text { concepts relevant to the subject }\end{array}$ & 2.33 & 0.79 & Low & 2 \\
\hline 3 & $\begin{array}{l}\text { I study the results of electronic pre-tests to identify the learners' } \\
\text { strength and weakness points }\end{array}$ & 2.3 & 0.82 & Low & 4 \\
\hline 4 & $\begin{array}{l}\text { I utilize synchronous and asynchronous communication tools to hold } \\
\text { discussions with learners to evaluate the knowledge and skills they possess. }\end{array}$ & 2 & 0.87 & Low & 5 \\
\hline 5 & $\begin{array}{l}\text { I use e-assessment techniques to identify the learners' attitude towards } \\
\text { the topics of the subject }\end{array}$ & 2.15 & 0.73 & Low & 3 \\
\hline 6 & I adopt the KWL model in the learners' diagnostic e-assessment process & 2.68 & 0.74 & Medium & 1 \\
\hline \multicolumn{2}{|r|}{ Total } & 2.21 & 0.82 & \multicolumn{2}{|l|}{ low } \\
\hline
\end{tabular}

According to table 6, there was a low degree of utilizing the techniques of diagnostic e-assessment among faculty members. All the items of the first domain got a low degree, except for one item, 'I adopt the KWL model in the learners' diagnostic e-assessment process', which got a medium degree. It can be interpreted that most faculty tend to conduct a quick discussion about the topic in question before delivering the lecture. In addition, the utilization of the traditional methods of diagnostic preassessment is still predominant in most Saudi universities. Further, most faculty also belief that diagnostic e-assessment techniques consume a lot of time and effort that could be added to their already heavy teaching and administrative loads. As asserted by Thubaiti (2018), traditional assessment methods are still prevalent among faculty who demonstrated a low degree of employing e-assessment techniques. This result is consistent with Al-Ruqy (2017) concluding that there was a low degree of utilizing diagnostic e-assessment techniques among teachers of natural science in Saudi Arabia.

To answer the second question, What is the degree of utilizing formative e-assessment techniques at the College of Education, Prince Sattam bin Abdulaziz University from faculty perspectives? The participants' responses to the second domain were analyzed as illustrated in table 7. 
Table 7: The participants' responses to the second domain of the questionnaire

\begin{tabular}{|l|l|c|c|c|c|}
\hline S. & Formative e-assessment & $\begin{array}{c}\text { Arithmetic } \\
\text { mean }\end{array}$ & $\begin{array}{c}\text { standard } \\
\text { deviation }\end{array}$ & Degree & Rank \\
\hline 1 & $\begin{array}{l}\text { I use short quizzes to measure the learners' understanding of the } \\
\text { subject. }\end{array}$ & 0.98 & 3.1 & Medium & 5 \\
\hline 2 & $\begin{array}{l}\text { I employ formative e-assessment methods to stimulate the learners' } \\
\text { higher thinking skills }\end{array}$ & 0.93 & 3.48 & high & 2 \\
\hline 3 & $\begin{array}{l}\text { I employ the tools available on the Blackboard LMS in formative e- } \\
\text { assessment }\end{array}$ & 0.89 & 3.25 & Medium & 3 \\
\hline $4 \begin{array}{l}\text { I utilize e-portfolios to know how learners have mastered the subject } \\
\text { taught }\end{array}$ & 0.83 & 2.85 & Medium & 7 \\
\hline 5 & $\begin{array}{l}\text { I encourage learners to design electronic concept maps to evaluate } \\
\text { specific objectives }\end{array}$ & 0.95 & 3.05 & Medium & 6 \\
\hline 6 & $\begin{array}{l}\text { I use do-now electronic activities and exercises to assess some cognitive } \\
\text { or skillful aspects }\end{array}$ & 0.92 & 2.78 & Medium & 9 \\
\hline 7 & $\begin{array}{l}\text { I employ formative e-assessment techniques that support effective } \\
\text { participation among learners. }\end{array}$ & 0.96 & 2.83 & Medium & 8 \\
\hline 8 & I assign individual /group e-projects to the learners & 0.89 & 3.63 & high & 1 \\
\hline 9 & I encourage learners to reflect on their e-portfolios (self-assessment) & 0.8 & 3.2 & Medium & 4 \\
\hline Total & 3.13 & 0.84 & Medium \\
\hline
\end{tabular}

Table 7 indicates a medium degree of utilizing formative e-assessment techniques. All the items of the second domain obtained a medium response degree except for two items, 'I employ formative eassessment methods to stimulate the learners' higher thinking skills' and 'I assign individual /group e-projects to the learners', which obtained high response degrees. These results revealed faculty uses formative e-assessment techniques more than diagnostic e-assessment. Faculty tend to pay more attention to this stage of evaluation, in terms of assigning a variety of tasks to the learners, such as eprojects, designing concept maps, do-now e-exercises as well as short quizzes. These results highlight the need to provide faculty with more training on the use of the techniques of e-assessment (Aganzouri, 2017). Al-Anzi (2019) agreed that there was a medium degree of utilizing e-assessment, while Al-Ruqy (2017) showed a low degree of utilizing the techniques of formative e-assessment among natural science teachers in Saudi Arabia.

To answer the third question, What is the degree of utilizing summative e-assessment techniques at the College of Education, Prince Sattam bin Abdulaziz University from faculty perspectives? The participants' responses to the third domain of the questionnaire were analyzed as demonstrated in table 8.

Table 8: Participants' responses to the third domain of the questionnaire

\begin{tabular}{|l|l|c|c|c|c|}
\hline S. & Summative e-assessment & $\begin{array}{c}\text { Arithmetic } \\
\text { mean }\end{array}$ & $\begin{array}{c}\text { standard } \\
\text { deviation }\end{array}$ & Degree & Rank \\
\hline 1 & $\begin{array}{l}\text { I concentrate on periodic e-assignments to evaluate the } \\
\text { accomplishment of different learning outcomes among learners }\end{array}$ & 0.96 & 3.2 & Medium & 4 \\
\hline 2 & $\begin{array}{l}\text { I afford learners with e-essay questions that measure their higher } \\
\text { thinking skills }\end{array}$ & 0.94 & 3.03 & Medium & 5 \\
\hline 3 & I utilize a variety of questions to measure the different learning outcomes & 1 & 3.38 & Medium & 2 \\
\hline 4 & I provided a performance feedback for each learner via the academic email & 0.91 & 3.53 & High & 1 \\
\hline 5 & $\begin{array}{l}\text { I mark examinations electronically and I instantly send the results for } \\
\text { the learners via the academic email }\end{array}$ & 0.93 & 2.95 & Medium & 6 \\
\hline 6 & $\begin{array}{l}\text { I follow up on the learners' marks and performances in assignments and } \\
\text { various projects by keeping record of these results in the e-portfolios }\end{array}$ & 0.85 & 3.33 & Medium & 3 \\
\hline & & & & & \\
\hline
\end{tabular}




\begin{tabular}{|c|c|c|c|c|c|}
\hline S. & Summative e-assessment & $\begin{array}{c}\text { Arithmetic } \\
\text { mean }\end{array}$ & $\begin{array}{l}\text { standard } \\
\text { deviation }\end{array}$ & Degree & Rank \\
\hline 7 & $\begin{array}{l}\text { I use the statistical analysis appropriate for the examination results to } \\
\text { identify the learners' strength and weakness points }\end{array}$ & 0.77 & 2.4 & Low & 9 \\
\hline 8 & $\begin{array}{l}\text { I use the discussion boards to follow up on the learners 'comments } \\
\text { about the subject content }\end{array}$ & 0.94 & 2.8 & Medium & 7 \\
\hline 9 & I send e-notifications for low-achievers via the academic e-mail & 0.98 & 2.78 & Medium & 8 \\
\hline & tal & 2.78 & 0.98 & \multicolumn{2}{|c|}{ Medium } \\
\hline
\end{tabular}

Data in table 8 revealed that there was a medium degree of utilizing summative e-assessment techniques among faculty. All items of the third domain got a medium response degree except for an item, 'I use the statistical analysis appropriate for the examination results to identify the learners' strength and weakness points', which got a low degree. It can be explained that the participants were inexperienced of applying the statistical analysis of the examination results. Additionally, they might prefer to treat the results of each student separately and sending personal reports via the email. This explanation was enhanced by the high response degree given to this item: I provided a performance feedback for each learner via the academic email. As indicated by the participants' responses, they utilize many techniques of summative e-assessment, including e-assignments, essay questions, marking examination electronically, e-portfolios and discussion boards. However, this result is inconsistent with Al-Ruqy (2017), which reached a low degree of utilizing summative e-assessment techniques among teachers of natural sciences.

To answer the fourth question, Were there statistically significant differences at the significance level of $\geq \alpha 0.05$ in the participants' mean responses to the degree of utilizing e-assessment techniques due to gender, academic degree, and years of experience? The significance of the differences in the participants' responses to each variable was calculated separately as follows:

a. Independent-samples T-test was conducted to calculate the significance of the differences in the participants' responses due to gender. The resulted data were explained in table 9.

Table 9: Significance of differences in the participants' responses according to gender

\begin{tabular}{|c|c|c|c|c|c|c|c|c|}
\hline Domain & Gender & No. & Mean & $\begin{array}{l}\text { standard } \\
\text { deviation }\end{array}$ & $\begin{array}{l}\text { Degree of } \\
\text { freedom }\end{array}$ & $\mathrm{T}$ value & $P$ value & $\begin{array}{c}\text { Significance } \\
\text { level }\end{array}$ \\
\hline \multirow{2}{*}{ Diagnostic e-assessment } & male & 31 & 2.40 & 0.86 & \multirow{2}{*}{68} & \multirow{2}{*}{1.71} & \multirow{2}{*}{0.09} & \multirow{2}{*}{ insignificant } \\
\hline & female & 39 & 2.09 & 0.64 & & & & \\
\hline \multirow{2}{*}{ Formative e-assessment } & male & 31 & 3.10 & 0.52 & \multirow{2}{*}{68} & \multirow{2}{*}{0.90} & \multirow{2}{*}{0.37} & \multirow{2}{*}{ insignificant } \\
\hline & female & 39 & 3.22 & 0.56 & & & & \\
\hline \multirow{2}{*}{ Summative e-assessment } & male & 31 & 3.11 & 0.45 & \multirow{2}{*}{68} & \multirow{2}{*}{0.467} & \multirow{2}{*}{0.64} & \multirow{2}{*}{ insignificant } \\
\hline & female & 39 & 3.04 & 0.46 & & & & \\
\hline \multirow{2}{*}{ Total } & male & 31 & 2.87 & 0.45 & \multirow{2}{*}{68} & \multirow{2}{*}{0.874} & \multirow{2}{*}{0.38} & \multirow{2}{*}{ insignificant } \\
\hline & female & 39 & 2.79 & 0.38 & & & & \\
\hline
\end{tabular}

Data illustrated in table 9 showed that there were no statistically significant differences in the participants' responses due to gender for each domain of the questionnaire and accordingly the total questionnaire. This result is consistent with Thubaiti (2018) and Aganzouri (2017) regarding no statistically significant differences in the participants' responses to the use of the e-assessment due to gender. However, these results differ to the results of Al-Jadea (2017).

b. ANOVA test was employed to calculate the significance of the differences in the participants' responses due to academic degree, i.e. assistant professor, associate professor and professor. Table 10 displays the results. 
Table 1o: Significance of differences in the participants' responses due to academic degree

\begin{tabular}{|c|c|c|c|c|c|c|c|}
\hline Domain & $\begin{array}{l}\text { Source of } \\
\text { variance }\end{array}$ & $\begin{array}{l}\text { Sum of } \\
\text { squares }\end{array}$ & $\begin{array}{c}\text { Mean } \\
\text { squares }\end{array}$ & $\begin{array}{l}\text { Degree of } \\
\text { freedom }\end{array}$ & F value & $P$ value & $\begin{array}{c}\text { Significance } \\
\text { level }\end{array}$ \\
\hline \multirow{3}{*}{ Diagnostic e-assessment } & Between groups & 0.254 & 0.127 & 2 & \multirow{3}{*}{0.214} & \multirow{3}{*}{0.808} & \multirow{3}{*}{ insignificant } \\
\hline & Within groups & 39.818 & 0.594 & 67 & & & \\
\hline & Total & 40.07 & & 69 & & & \\
\hline \multirow{3}{*}{ Formative e-assessment } & Between groups & 1.388 & 0.694 & 2 & \multirow{3}{*}{2.42} & \multirow{3}{*}{0.096} & \multirow{3}{*}{ insignificant } \\
\hline & Within groups & 19.148 & 0.286 & 67 & & & \\
\hline & Total & 20.53 & & 69 & & & \\
\hline \multirow{3}{*}{ Summative e-assessment } & Between groups & 0.276 & 0.138 & 2 & \multirow{3}{*}{0.646} & \multirow{3}{*}{0.528} & \multirow{3}{*}{ insignificant } \\
\hline & Within groups & 14.328 & 0.214 & 67 & & & \\
\hline & Total & 14.597 & & 69 & & & \\
\hline \multirow{3}{*}{ Total } & Between groups & 0.044 & 0.022 & 2 & \multirow{3}{*}{0.145} & \multirow{3}{*}{0.865} & \multirow{3}{*}{ insignificant } \\
\hline & Within groups & 10.154 & 0.152 & 67 & & & \\
\hline & Total & 10.198 & & 69 & & & \\
\hline
\end{tabular}

According to table 10, there were no statistically significant differences in the participants' responses due to academic degree to each domain of the questionnaire and accordingly the total questionnaire. These results are consistent Al-Anzi (2019) and Aganzouri (2017) and inconsistent with Thubaiti (2018) which showed statistically significant differences in the participants' responses to an eassessment questionnaire due to academic degree.

c. ANOVA test was employed to calculate the significance of the differences in the participants' responses due to years of experience, i.e. less than 5 years, 5 years, less than 10 years and more than 10 years. Table 11 demonstrates the results.

Table 11: Significance of differences in the participants' responses due to years of experience

\begin{tabular}{|c|c|c|c|c|c|c|c|}
\hline Domain & \begin{tabular}{|l}
$\begin{array}{l}\text { Source of } \\
\text { variance }\end{array}$ \\
\end{tabular} & \begin{tabular}{|l} 
Sum of \\
squares
\end{tabular} & $\begin{array}{c}\text { Mean } \\
\text { squares }\end{array}$ & \begin{tabular}{|c}
$\begin{array}{c}\text { Degree of } \\
\text { freedom }\end{array}$ \\
\end{tabular} & F value & $P$ value & $\begin{array}{c}\text { Significance } \\
\text { level }\end{array}$ \\
\hline \multirow{3}{*}{ Diagnostic e-assessment } & Between groups & 2.29 & 1.147 & 2 & \multirow{3}{*}{2.03} & \multirow{3}{*}{0.139} & \multirow{3}{*}{ insignificant } \\
\hline & Within groups & 37.77 & 0.564 & 67 & & & \\
\hline & Total & 40.07 & & 69 & & & \\
\hline \multirow{3}{*}{ Formative e-assessment } & Between groups & 1.25 & 0.025 & 2 & \multirow{3}{*}{2.17} & \multirow{3}{*}{0.122} & \multirow{3}{*}{ insignificant } \\
\hline & Within groups & 19.28 & 0.288 & 67 & & & \\
\hline & Total & 20.53 & & 69 & & & \\
\hline \multirow{3}{*}{ Summative e-assessment } & Between groups & 0.269 & 0.135 & 2 & \multirow{3}{*}{0.629} & \multirow{3}{*}{0.536} & \multirow{3}{*}{ insignificant } \\
\hline & \begin{tabular}{|l|} 
Within groups \\
\end{tabular} & 14.329 & 0.214 & 67 & & & \\
\hline & Total & 14.597 & & 69 & & & \\
\hline \multirow{3}{*}{ Total } & Between groups & 0.015 & 0.008 & 2 & \multirow{3}{*}{0.049} & \multirow{3}{*}{0.952} & \multirow{3}{*}{ insignificant } \\
\hline & \begin{tabular}{|l} 
Within groups \\
\end{tabular} & 10.183 & 0.152 & 67 & & & \\
\hline & Total & 10.198 & & 69 & & & \\
\hline
\end{tabular}

Table 11 indicated no statistically significant differences in the participants' responses due to years of experience in each domain of the questionnaire and accordingly the total questionnaire. These results are consistent the results concluded by Al-Anzi (2019) and Thubaiti (2018).

\section{Recommendations}

In light of the results of the current study, Saudi universities are recommended to expand the use of the various forms of e-assessment, including diagnostic, formative and summative e-assessment. Further, Saudi universities should encourage faculty to utilize the techniques of e-assessment and to 
consider it in the evaluation of the learners' performance. The study also highly recommends holding training courses for faculty in Saudi universities in order to develop their technical skills that enable them to use e-assessment tools.

For future studies, it is important to identify the training needs among faculty members in various Saudi universities regarding the use of e-assessment. Additionally, addressing the obstacles that hinder the implementation of e-assessment in various Saudi universities is of great significance. Finally, future studies may highlight the impact of utilizing the techniques of e-assessment on the different aspects of learning and teaching of various courses.

\section{Conclusion}

The current study highlighted the fundamental role of e-assessment in supporting the modern educational reforms and the process of integrating technology in education. Accordingly, various forms of e-assessment, i.e. diagnostic, formative and summative e-assessment should be enhanced in various educational stages. The current study identified the degree of utilizing the techniques of eassessment in Prince Sattam Bin Abdulaziz University from faculty perspectives. The primary limitation of this study is its sample, since it is limited to faculty. Future studies may handle this limitation by exploring the use of e-assessment from the perspective of other sample groups, such as students. The study also has temporal and spatial limits since it was conducted during the second semester of the academic year 2019/2020 and the participants belong to one institution. However, these limits make the results unique.

\section{References}

Abdulaziz, H. (2008). E-learning: Philosophy, principles, tools, and applications. Amman: Dar Al-Fikr.

Abdelatti, H. (2015). Patterns of performance support and measuring their effect on promoting Faculty skills of eassessment on Blackboard LMS and their attitudes towards it. Educational Sciences, 15(4), 233-350.

Aboukhatwa, E. (2013). The effect of distance training program with the aid of virtual classrooms in the development of electronic evaluation skills and attitudes toward distance training of the faculty members. Ajman Journal of Studies and Research, 13(1), 1-29.

Abu-Aish, B. (2016). Assessment methods of learning outcomes for Taif University students in the light of quality assurance standards. Journal of Educational Sciences- Qena Faculty of Education, 27, 13-70.

Ahmed, E. (2016). The e- formative evaluation methods in massive open online courses and its impact on achievement motivation and developing the skills of using content management systems for graduate students of King Saud University. ASEP, 76, 17-66.

Aganzouri, A. (2017). Faculty attitudes towards employing Blackboard assessment tools in the educational process at Al-Jouf University. Assessment symposium in university education, the foundations and aspirationsCollege of Education, Al-Jouf University, 127-139.

Al-Anzi, K. (2019). The degree of using of e-assessment tools among middle school teachers of social and national studies in Hafar Al-Batin Governorate. Journal of Educational and Psychological Sciences, 3(19), 59-79.

Al-Asr, S. (2015). Two patterns of synchronous and asynchronous collaborative e learning and their impact on developing skills for using e-assessment tools and motivation for learning. Educational Technology, 25(4), 89-157.

Al-Gharib, Z. (2009). E-courses: Design, production, publishing, application, and evaluation. Cairo: The World of Books .

Al-Hirdi, S. (2017). The reality of using e-assessment tools among secondary school teachers of social and national studies in Riyadh and a proposal for its development. World of Education- Arab Institution for Scientific Consultation and Human Resources Development, 57, 1-25.

Al-Jadea, M. (2017). Trends of faculty towards conducting online exams and the obstacles to its application in Tabuk University. The International Interdisciplinary Journal of Education, 6(2), 77-87.

Al-Nagem, M. (2016). Effectiveness of a training program based on the subject evaluation criteria of using eportfolio to improve the performance of forensic science teachers at middle school. Arabian Gulf Letter, $37(141), 35-54$. 
Al-Ruqy, A. (2017). The degree of natural sciences teachers' practice of e-assessment methods in the intermediate stage [unpublished Master's Thesis]. Imam Muhammad bin Saud Islamic University, Riyadh.

Alsaadon, H. (2017). Students' perception of e-assessment at Saudi electronic university. Turkish On-line Journal of Educational technology, 16 (1), 147-153.

Al-Shammari, E., Abdulaziz, M. \& Muhammad, H. (2017). Effectiveness of a proposed training program to develop skills for preparing and using e-portfolio among faculty. Educational Journal- Faculty of Education, Sohag University, 50, 28-59.

Appiah, M., Tonder, F. (2018). E-Assessment in higher education: A review. International journal of business and economic research, 9(6), 1454-146o.

Atallah, M. (2016). Attitudes of students and faculty at Mansoura University towards e-assessment and its application obstacles. Educational and psychological studies- Faculty of Education, Zagazig University, 90, 201-247.

Ayo, C. K., Akinyemi, I. O., Adebiyi, A. \& Ekong, U. (2007). The prospects of e-examination implementation in Nigeria: Administration and management. Turkish Online Journal of Distance Education, 3(6), 42-53.

Baker, E. \& Gordon, E. (2014). From the Assessment OF Education to the Assessment FOR Education: Policy and Futures. Teachers College Record, 116(11), 1-24.

Baleni Z. (2015). Online formative assessment in higher education: Its pros and cons. The Electronic Journal of eLearning, 13(4), 228-236.

Fathallah, M. (2006). Educational Evaluation (2 ${ }^{\text {nd }}$ ed.). Riyadh: International Publishing House.

Honarmand, M. (2009). Computer aided assessment and its situation in higher education: A case study from the Islamic Azad University in Iran. International Conference on Information Management and Engineering, Information Management and Engineering. ICIME 'o9.

Osuji, S. (2017). The use of e-assessment in the Nigerian higher systems. Turkish Online Journal of Distance Education, 13(4), 140-152.

Reju, S. A., \& Adesina, A. (2009). Fundamentals of online examinations. Paper presented at a training workshop for academic staff on on-line examination system in National Open University of Nigeria, the Model Study Center Computer Laboratory, Lagos, November 5-9.

Schultz, K. (2009). Rethinking classroom participation: Listening to silent voices. New York: Teachers College Press.

Stodberg, U. (2012). A research review of e-assessment. Assessment E Evaluation in Higher Education, 37(5), 591604.

Thubaiti, O. (2018). Evaluation methods used by faculty in relation to the quality of learning outcomes among Shaqra University students, Saudi Arabia. The Educational Journal, 51, 322-352.

Walker, D., Topping, K. \& Rodrigues, S. (2008). Student reflection on formative e-assessment expectations and perceptions. Learning, Media and Technology, 33(3), 221-234.

Zaytoon, H. (2005). A new vision in education: Concept, issues, application, and evaluation in e-learning. Riyadh: AlSaltieh Educational House. 